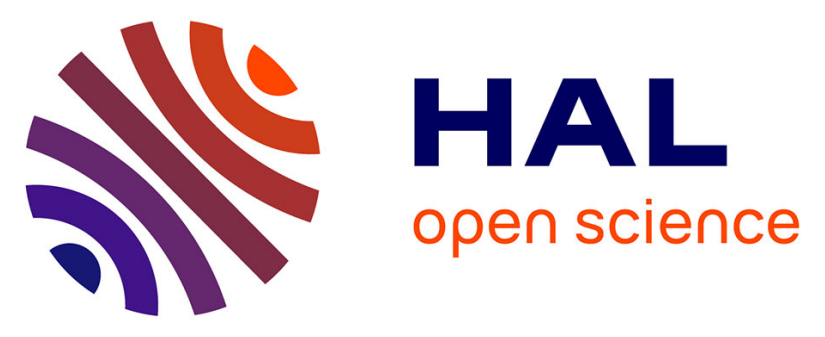

\title{
Isomeric Effect of Mercaptobenzoic Acids on the Synthesis, Stability, and Optical Properties of Au 25 (MBA) 18 Nanoclusters
}

Franck Bertorelle, Isabelle Russier-Antoine, Clothilde Comby-Zerbino, Fabien Chirot, Philippe Dugourd, Pierre-Francois Brevet, Rodolphe Antoine

\section{To cite this version:}

Franck Bertorelle, Isabelle Russier-Antoine, Clothilde Comby-Zerbino, Fabien Chirot, Philippe Dugourd, et al.. Isomeric Effect of Mercaptobenzoic Acids on the Synthesis, Stability, and Optical Properties of Au 25 (MBA) 18 Nanoclusters. ACS Omega, 2018, 3 (11), pp.15635-15642. 10.1021/acsomega.8b02615 . hal-02108463

\section{HAL Id: hal-02108463 https://hal.science/hal-02108463}

Submitted on 6 Nov 2020

HAL is a multi-disciplinary open access archive for the deposit and dissemination of scientific research documents, whether they are published or not. The documents may come from teaching and research institutions in France or abroad, or from public or private research centers.
L'archive ouverte pluridisciplinaire HAL, est destinée au dépôt et à la diffusion de documents scientifiques de niveau recherche, publiés ou non, émanant des établissements d'enseignement et de recherche français ou étrangers, des laboratoires publics ou privés. 


\title{
Isomeric Effect of Mercaptobenzoic Acids on the Synthesis, Stability, and Optical Properties of $\mathrm{Au}_{25}(\mathrm{MBA})_{18}$ Nanoclusters
}

\author{
Franck Bertorelle, ${ }^{\dagger}$ Isabelle Russier-Antoine, ${ }^{\dagger}$ Clothilde Comby-Zerbino, $^{\dagger}$ Fabien Chirot, ${ }^{\ddagger}$
} Philippe Dugourd, ${ }^{\dagger[0}$ Pierre-François Brevet, ${ }^{\dagger}$ and Rodolphe Antoine ${ }^{*},{ }^{\dagger}$ (i)

${ }^{\dagger}$ Univ Lyon, Université Claude Bernard Lyon 1, CNRS, Institut Lumière Matière, UMR 5306, 69100 Villeurbanne, France

${ }^{\ddagger}$ Univ Lyon, CNRS, Université Claude Bernard Lyon 1, ENS de Lyon, Institut des Sciences Analytiques, UMR 5280, 5 rue de la Doua, 69100 Villeurbanne, France

\section{Supporting Information}

ABSTRACT: We report a simple size focusing, two-step "bottom-up" protocol to prepare water-soluble $\mathrm{Au}_{25}(\mathrm{MBA})_{18}$ nanoclusters, using the three isomers of mercaptobenzoic acids $(p / m / o-\mathrm{MBA})$ as capping ligands and $\mathrm{Me}_{3} \mathrm{NBH}_{3}$ as a mild reducing agent. The relative stability of the gas-phase multiply deprotonated $\mathrm{Au}_{25}(\mathrm{MBA})_{18}$ ions was investigated by collision-induced dissociation. This permitted us to evaluate the possible isomeric effect on the $\mathrm{Au}-\mathrm{S}$ interfacial bond stress. We also investigated their optical properties. The absorption spectra of $\mathrm{Au}_{25}(\mathrm{MBA})_{18}$ isomers were very similar and showed bands at 690, 470, and $430 \mathrm{~nm}$. For all $\mathrm{Au}_{25}(\mathrm{MBA})_{18}$ isomeric clusters, no measurable one-photon excited fluorescence under UV-vis light was found, in neither solid- nor solution-state. The two-photon excited emission spectra and first hyperpolarizabilities of the clusters were also determined. The results are discussed in terms of the possible isomeric effect on excitations within the metal core and the possibility of charge transfer excitations from the ligands to the metal nanocluster.

\section{INTRODUCTION}

Liganded noble metal nanoclusters (NCs) can be produced with atomic precision ${ }^{1}$ and are of great potential for applications in various fields where the structure-property correlations are key parameters. ${ }^{2}$ Among the plethora of NCs for which crystal structures have been reported, $\mathrm{Au}_{25}(\mathrm{SR})_{18}$ (where SR stands for a chemical group containing a sulfur atom) stimulated tremendous interest both experimentally ${ }^{3-5}$ and theoretically ${ }^{6,7}$ because of its ease of preparation and functionalization, and also to its fascinating optical, ${ }^{8}$ chiroptical, ${ }^{9,10}$ magnetic, ${ }^{11}$ and electrochemical properties. ${ }^{12,13}$ An updated summary in the related investigations of $\mathrm{Au}_{25}(\mathrm{SR})_{18}$ has been recently reported in the review of $\mathrm{Zhu}$ and co-workers. ${ }^{14}$

$\mathrm{Au}_{25}$ NCs have been capped mainly by thiol ligands. More than 50 thiol ligands have been reported so far for producing $\mathrm{Au}_{25}(\mathrm{SR})_{18}$ using methods based on in situ, one-pot synthesis or on the ligand-exchange method from a templated $\mathrm{Au}_{25}(\mathrm{SR})_{18}{ }^{14}$ This has permitted to investigate the possible role of the chemical group covalently attached to sulfur in thiol ligands on many physicochemical properties of $\mathrm{Au}_{25} \mathrm{NCs}$, particularly their optical properties. ${ }^{8}$ The role of ligands has permitted in some cases to propose ligand engineering strategies to tune these properties. The ligand effect on their emission properties was investigated in the seminal paper of $\mathrm{Wu}$ and Jin. ${ }^{8}$ Both the total number of charges in the gold core and the nature of the ligand were found to influence the fluorescence. In particular, the nature of capping ligands was found to affect both the charge transfer from the ligands to the metal core via the $\mathrm{Au}-\mathrm{S}$ bonds and the donation of delocalized electrons of the ligands to the metal core. In contrast, the investigation of the role of ligands to the nonlinear optical (NLO) properties of $\mathrm{Au}_{25}(\mathrm{SR})_{18}$ is still in its infancy, and only a few studies on NLO measurements have been published. ${ }^{15,16}$ We reported recently that the first hyperpolarizability value $(\beta)$ responsible for second harmonic response was very similar between cysteine and glutathione (a cysteine containing peptide) as ligands. ${ }^{17}$ Verbiest and co-workers ${ }^{18}$ found a drastic dependence of the hyperpolarizability value on the surface ligand chirality.

However, so far, the ligand's role on physicochemical properties of $\mathrm{Au}_{25} \mathrm{NCs}$ was mainly explored by changing the structure and the bulkiness of protecting thiols. Surprisingly, the isomeric effect of thiolate molecules on the synthesis and optical properties of metal NCs was only scarcely investigated. The role of sterics (using three different tolyl ligands) in phosphine-ligated gold clusters was investigated very recently. ${ }^{19}$ Also, Jin and co-workers ${ }^{20}$ demonstrated that three

Received: October 1, 2018

Accepted: November 5, 2018

Published: November 16, 2018 
Scheme 1. Illustration of the Synthesis Protocol of $A_{25}(\mathrm{MBA})_{18}$ NCs

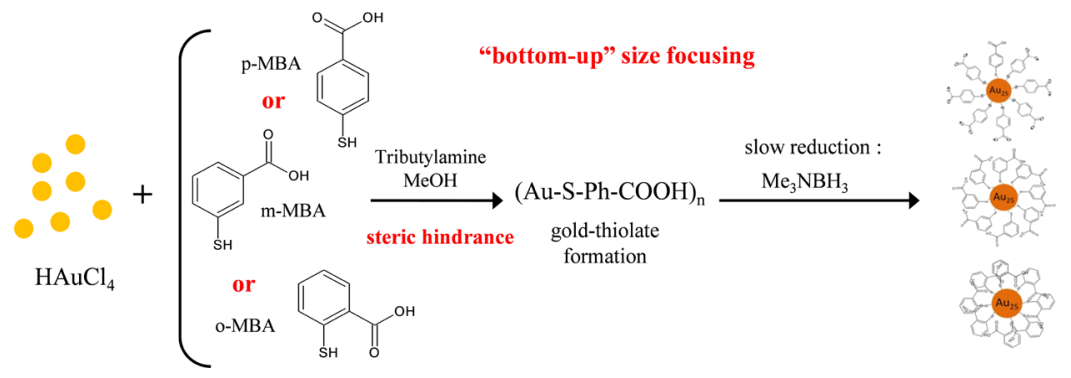

isomeric methylbenzenethiols $(p / m / o-M B T)$ can have significant effects on the resulting size of gold NCs. Azubel et al. ${ }^{21}$ and Tero et al. $^{22}$ recently reported on the ligand-metal interfacial interactions in gold NCs protected by metamercaptobenzoic acid and pointed out weak $\pi-\mathrm{Au}$ and $\mathrm{O}=$ $\mathrm{C}-\mathrm{OH} \cdots \mathrm{Au}$ interactions between $m-\mathrm{MBA}$ and Au clusters. On the other hand, Chang and co-workers ${ }^{23}$ evidenced isomeric effects of mercaptobenzoic acids (MBA) on the synthesis and fluorescence of copper NCs aggregates. In particular, different $\mathrm{pH}$-dependent optical properties were reported, allowing differentiation of the three isomers of mercaptobenzoic acids $(p / m / o-M B A)$.

In this work, we investigate the isomeric effect of MBA on the preparation and optical properties of $A_{25}(\mathrm{MBA})_{18} \mathrm{NCs}$. We report for the first time a simple size focusing synthesis of $\mathrm{Au}_{25}(\mathrm{MBA})_{18} \mathrm{NCs}$, with the three isomers of mercaptobenzoic acid $(p / m / o-M B A)$ (Scheme 1$)$. The relative stability of the three isomeric $\mathrm{Au}_{25}(\mathrm{MBA})_{18}$ was investigated by collisioninduced dissociation (CID). This permits evaluation of the effect of ligand isomerization on the relative stability of the three clusters. We also investigate their NLO properties after an initial two-photon process. First hyperpolarizabilities, as obtained by the hyper-Rayleigh scattering (HRS) technique, and two-photon excited emission spectra of these isomeric clusters are thus presented. The results are discussed in terms of the possible isomeric effect on the leading two-photon excitation process.

\section{RESULTS AND DISCUSSION}

Ligands used in this work are 2, 3 or 4-mercaptobenzoic acid (ortho, meta, or para isomers of MBA) which only differs by the position of the carboxylic group on the phenyl ring. Because many factors may affect the size selectivity of AuNCs synthesis, including solution conditions and the strength of the reducing agent, we used the exact same procedure for the syntheses based on each considered isomer (see the Experimental Section for details). This procedure typically involves a "bottom-up" size focusing by a two-step process (Scheme 1): (i) reduction of $\mathrm{Au}(\mathrm{III})$ to $\mathrm{Au}(\mathrm{I})$ forming ( $\mathrm{Au}-$ $\mathrm{S}-\mathrm{Ph}-\mathrm{COOH})_{n}$ intermediate complexes and (ii) slow reduction of $\mathrm{Au}(\mathrm{I})$ to $\mathrm{Au}(0)$ by a mild reducing agent (e.g., $\mathrm{Me}_{3} \mathrm{NBH}_{3}$ ). It is thought that this two-step process generates small size gold-thiolate intermediates that lead ultimately to the formation of $\mathrm{Au}_{25}$ clusters, thereby supporting the "bottom-up" terminology employed. In the first step, the ionpairing between the carboxylic group and tributylamine allows for the solubility of gold-thiolate intermediates formed during the reaction and increases the steric hindrance of the carboxylic group, thus limiting the formation of large-size gold-thiolate intermediates. Of note, without tributylamine, the goldthiolate complexes are not soluble. In the second step, by using
$\mathrm{Me}_{3} \mathrm{NBH}_{3}$ as a mild reducing agent, the reduction of goldthiolate intermediates is slow enough to allow cluster formation and rearrangement leading mainly to the most stable $\mathrm{Au}_{25}$ cluster size, by a kinetically controlled process. ${ }^{24}$

Starting with $100 \mathrm{mg}(2.55 \mathrm{mmol})$ of tetrachloroauric acid trihydrate $\left(\mathrm{HAuCl}_{4}, 3 \mathrm{H}_{2} \mathrm{O}\right)$, we isolate after purification $73 \mathrm{mg}$ of $\mathrm{Au}_{25}(m-\mathrm{MBA})_{18}(\approx 93 \%$ yield based on gold atom $), 32 \mathrm{mg}$ of $\mathrm{Au}_{25}(p-\mathrm{MBA})_{18}(\approx 40 \%$ yield $)$, and $16 \mathrm{mg}$ of $\mathrm{Au}_{25}(o-\mathrm{MBA})_{18}$ $(\approx 20 \%$ yield) [see polyacrylamide gel electrophoresis (PAGE) after purification, Figure $S 1$ in the Supporting Information]. Note that for $o-\mathrm{MBA}$, smaller sizes are also produced, as visible before purification. For $p$-MBA, $A_{36}(\mathrm{MBA})_{24}$ is also formed and can be isolated during the purification process. ${ }^{25}$ Clearly, an isomeric effect of mercaptobenzoic acids on the preparation of $\mathrm{Au}_{25}(\mathrm{MBA})_{18} \mathrm{NCs}$ is observed. This may be explained qualitatively based on steric hindrance of the carboxylic group (bulkiness of the carboxylic groups with respect to other benzene rings in the ligand shell, see Scheme 1) and its ionpairing with tributylamine. Indeed, $o$-MBA leads to a strong steric hindrance at the surface of the gold core and avoids the formation of large NCs. Consequently, smaller Au-MBA cluster sizes and (Au-MBA) $)_{n}$ polymers are produced in addition to $\mathrm{Au}_{25}(\mathrm{MBA})_{18}$. On the other hand, for $p$-MBA, the steric hindrance is reduced at the surface of the gold core, and then higher cluster size (in particular $\mathrm{Au}_{36}(\mathrm{MBA})_{24}$ ) can be produced. Interestingly, for $m$-MBA isomer, a yield of synthesis close to $100 \%$ is obtained. In that case, it is possible that a good match between the size of the ligand shell (in $\mathrm{Au}_{25}(\mathrm{MBA})_{18}$ ) and the steric hindrance brought by the carboxylic group in the metaposition (see Scheme 1) lead exclusively to the $\mathrm{Au}_{25}$ cluster size, by a kinetically controlled process.

The gold clusters produced by the synthesis described above were characterized by mass spectrometry and optical methods. The monodispersity in terms of the size of the prepared gold clusters was addressed by ESI-mass spectrometry and PAGE. $^{26}$ ESI mass spectra for the protected $\mathrm{Au}_{25}$ clusters with the three isomers (o-, $m$-, and $p$-MBA) and acquired under gentle ESI conditions are shown in Figure 1. A charge state distribution of general formula $\left[\mathrm{M}-n \mathrm{H}^{+}\right]^{(n+1)-}(2 \leq n \leq$ 6 ) is observed for the $\mathrm{Au}_{25}$ cluster with the three isomers (o-, $m-$, and $p$-MBA). Of note, the ESI mass spectrum in negative mode of $\mathrm{Au}_{25}(p-\mathrm{MBA})_{18}$ leads to a broader charge state distribution and higher charge states than the ones observed for $\mathrm{Au}_{25}(m-\mathrm{MBA})_{18}$ and $\mathrm{Au}_{25}(o-\mathrm{MBA})_{18}$. As illustrated in Figure S2 (see Supporting Information), the experimental isotopic distributions of the 3- species from each ligand isomer can be very well reproduced by simulated ones assuming that protons are removed from two of the MBA carboxyl groups. Because those two deprotonations account only for part of the total charge of the ions, we assumed that 

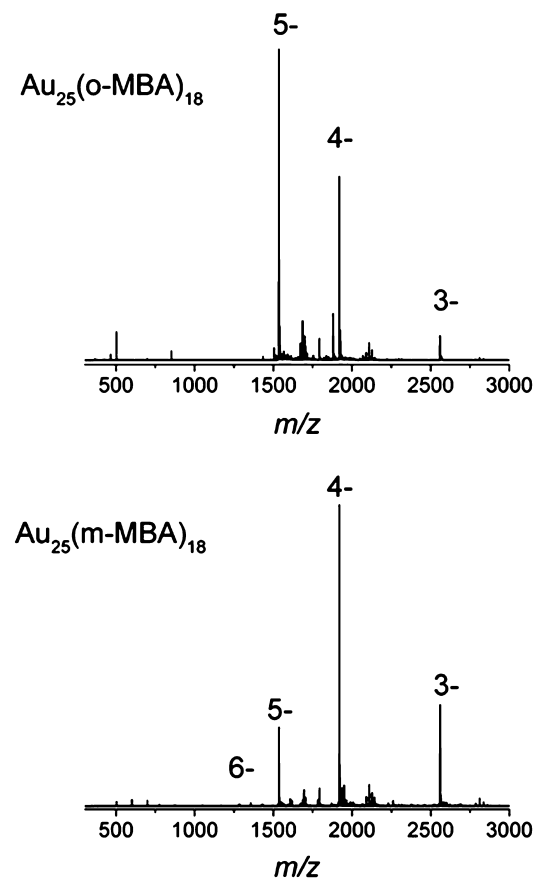

$6-$

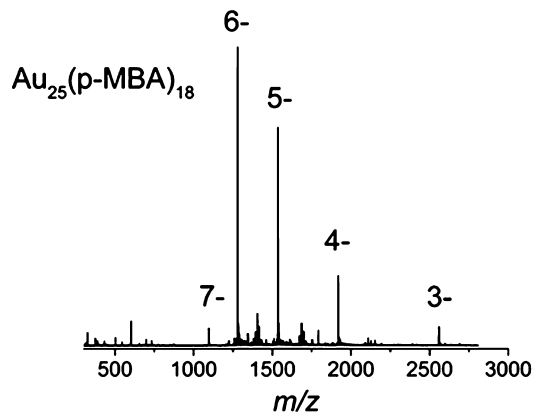

Figure 1. ESI mass spectra for the protected $\mathrm{Au}_{25}$ clusters from water solution acquired under gentle ESI conditions.

the gold cluster is bearing one net negative charge (leading to $\left.\left[\mathrm{M}-2 \mathrm{H}^{+}\right]^{3-}\right)$. Deconvolution of different charge states, using a multiplicative correlation algorithm, ${ }^{27}$ provided a mass of $7677 \mathrm{Da}$ for all isomers of $\mathrm{Au}_{25}$, consistent with the calculated mass of $\mathrm{Au}_{25}(\mathrm{MBA})_{18}$. Additionally, PAGE for $\mathrm{Au}_{25}$ clusters confirms the monodispersity in terms of the size of the prepared $\mathrm{Au}_{25}(\mathrm{MBA})_{18}$ isomeric clusters (see Figure $\mathrm{S} 1$ in the Supporting Information).

Figure 2 shows the UV-vis absorption spectra in water of the synthesized $\mathrm{Au}_{25}(\mathrm{MBA})_{18}$ isomeric clusters. The absorp-

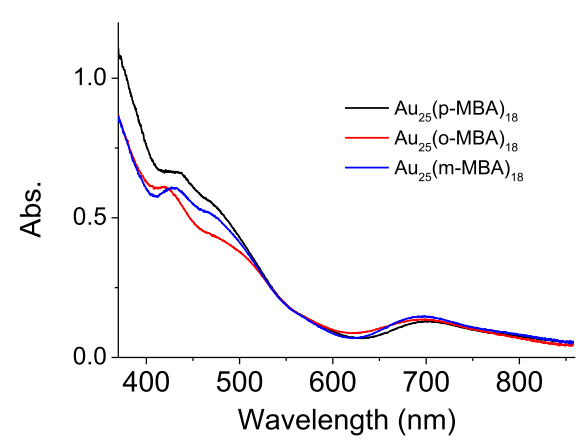

Figure 2. Absorption spectra of $\mathrm{Au}_{25}(\mathrm{MBA})_{18} \mathrm{NC}$ from water solution. tion spectra of $\mathrm{Au}_{25}(\mathrm{MBA})_{18}$ isomers show multiple bands at 690,470 , and $430 \mathrm{~nm}$ and are very similar to the ones reported and assigned for $\left[\mathrm{Au}_{25}(\mathrm{SR})_{18}\right]^{-} \mathrm{NCs}^{28,29}$ with different ligands. No significant isomer effect, except slight shifts in the position of bands, is observed on the absorption spectra. The fact that the absorption spectra of $\mathrm{Au}_{25}(\mathrm{MBA})_{18}$ isomers are similar to the 25-Au-atom cluster $\left(\mathrm{Au}_{25}\left(\mathrm{SCH}_{2} \mathrm{CH}_{2} \mathrm{Ph}\right)_{18}\right)$ (reported in ref 4 and for which a crystal structure has been obtained) may indicate that $\mathrm{Au}_{25}(\mathrm{MBA})_{18}$ isomers and $\mathrm{Au}_{25}\left(\mathrm{SCH}_{2} \mathrm{CH}_{2} \mathrm{Ph}\right)_{18}$ NCs have similar structural trends, although UV-vis absorption is not the method of choice to determine or compare structures.

In order to better structurally characterize our NCs, we conducted ion mobility-mass spectrometry (IM-MS) measurements. IM-MS is an emerging tool for the NC community, which allows separating mass selected ions based on the differences of their electrical mobility in a buffer gas. ${ }^{30-34}$ The IMS arrival time distributions (ATDs) are dominated by a single peak (ATDs for isomers of $\mathrm{Au}_{25}(\mathrm{MBA})_{18}$ are given in Figure S3); however, tails at shorter arrival times are also visible and are attributed to dynamical effects occurring during the flight. Such features are not attributed to coexistence of different isomers but to either fragmentation or electron loss. ${ }^{35}$ Absolute values for the collision cross section (CCS) of the $\mathrm{Au}_{25}(\mathrm{MBA})_{18}$ clusters were obtained by measuring their ATDs at different drift voltages and are displayed for different charge states in Figure S4 in Supporting Information. ${ }^{34}$ For low charge states (3-), the collision cross sections are very similar, whatever the isomer of MBA. This suggests that the three $\mathrm{Au}_{25}(\mathrm{MBA})_{18}$ isomers have a similar shape. For o-MBA isomeric $\mathrm{Au}_{25} \mathrm{NCs}$, the CCS does not depend on the charge state, while for $m$-MBA and $p$-MBA isomeric $\mathrm{Au}_{25} \mathrm{NCs}$, the higher the charge state, the larger the collision cross section. The change in cross section with the charge state for $m$-MBA and $p$-MBA may be correlated to the electron density on the negatively charged carboxylic group $\left(-\mathrm{COO}^{-}\right)$located on the surface of the NC which contributes to increase the CCSs, as observed by Dugourd, Jarrold, and co-workers for indium cluster anions. ${ }^{36}$ This is also correlated to the observation of higher charge states for these two species (Figure 1), with accommodation of electron density on the surface of the clusters, while on the third species, charges are expected to be localized within the ligand shell.

CID on gold NCs in mass spectrometers was reported in previous works for different charge states, in both positive and negative modes, and with different ligands. ${ }^{25,37-40}$ Usually, whatever the ligand, CID experiments lead to dissociation of the protecting ligand staples and formation of ions with higher$\mathrm{m} / \mathrm{z}$ ratios. Of note, the nature (protonation, deprotonation, counterion adducts, etc) as well as the number of charges affect the fragmentation pattern; however, the obtained fragments are not sufficient for structural characterization. Figure 3 displays the CID breakdown curves for the 4- charge state of $\mathrm{Au}_{25}(\mathrm{MBA})_{18}$ for the three isomeric MBA ligands. For $p$-MBA, almost no fragmentation is observed as a function of the collision energy (CE). Only a fragmentation yield of $\sim 2 \%$ is obtained at $82 \mathrm{eV}$ of $\mathrm{CE}$. $\mathrm{Au}_{25}$ with $m$-MBA ligands is found to be less stable than $p$-MBA ligands with a fragmentation yield of $\sim 30 \%$ at the same $\mathrm{CE}$. In great contrast, $\mathrm{Au}_{25}$ with o-MBA ligands appears to be dramatically more sensitive to collision activation. Fragmentation is visible even for $\mathrm{CE}=30 \%$, and total depletion of the precursor ion is reached yet at $\mathrm{CE}=90$ $\mathrm{eV}$, leading to numerous fragments (see Figure $\mathrm{S} 5$ in 


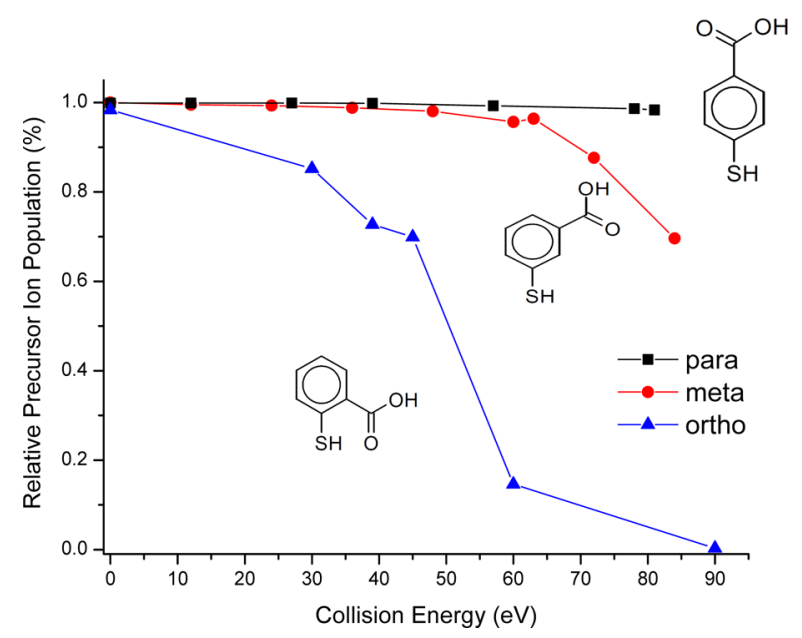

Figure 3. CID breakdown curves for the 4- charge state of $\mathrm{Au}_{25}(\mathrm{MBA})_{18}$ for the three isomeric MBA ligands as a function of collision energy (CE).

Supporting Information). For each $\left[\mathrm{Au}_{25}(\mathrm{MBA})_{18}\right]^{4-}$ precursor ion, the main fragmentation pathways upon CID entail losses of $\mathrm{Au}_{x}(\mathrm{MBA})_{\mathrm{y}}$ where $x=1$ and $y=2$ and, to a lesser extent, $x=2$ and $y=3$. It results in triply-charged products in the $2200-2600 \mathrm{~m} / \mathrm{z}$ range, and in the formation of the complementary singly-charged oligomers $\left[\mathrm{Au}(\mathrm{MBA})_{2}\right]^{-}$and $\left[\mathrm{Au}_{2}(\mathrm{MBA})_{3}\right]^{-}$in the $\mathrm{m} / \mathrm{z}$ range of 500-1000. These fragmentation patterns are very similar to those observed by Brodbelt, Whetten, and co-workers on negatively charged $\mathrm{Au}_{25}(p-\mathrm{MBA})_{18}$ by conventional CID and higher-energy collisional dissociation. ${ }^{25}$ Of note, the electron affinity of $\mathrm{Au}_{25}(\mathrm{SR})_{18}$ was reported to be as low as $2.2 \mathrm{eV},{ }^{41}$ and thus the electron detachment might compete with the CID. For $\left[\mathrm{Au}_{25}(\mathrm{MBA})_{18}\right]^{3-}$ and $\left[\mathrm{Au}_{25}(\mathrm{MBA})_{18}\right]^{4-}$ precursor ions, only fragmentation channels are observed, while for $\left[\mathrm{Au}_{25}(\mathrm{MBA})_{18}\right]^{5-}$ precursor ions (for the ortho isomer), electron detachment from collisionally heated clusters competes with fragmentation. These fragments contrast with those observed for multi-deprotonated $\mathrm{Au}_{25}(\mathrm{SG})_{18}$ ions by CID (SG for glutathione ligand), ${ }^{40}$ where the CID pathways involve successive losses of pyroglutamic acid coming from cleavage and reorganization of the glutamic acid side chain of SG. In this case, singly deprotonated $\mathrm{Au}_{2}(\mathrm{SG})_{2}$ and doubly deprotonated $\mathrm{Au}_{4}(\mathrm{SG})_{4}$ cluster ions were observed. ${ }^{40}$

Again, an isomeric effect of mercaptobenzoic acids on the gas-phase stability of $\mathrm{Au}_{25}(\mathrm{MBA})_{18} \mathrm{NCs}$ is observed. This may be accounted for by the steric hindrance of the carboxylic groups on the ligand shell. Indeed, $m-\mathrm{MBA}$ and, in particular, $o$-MBA ligands lead to a strong steric hindrance at the surface of the gold core leading to constraint on the $\mathrm{Au}-\mathrm{S}$ interface that may reduce the binding energy for fragmentation through the $\mathrm{Au}-\mathrm{S}$ bond breaking. Another important parameter that can explain the difference in CID breakdown curves for the 4charge state of $\mathrm{Au}_{25}(\mathrm{MBA})_{18}$ for the three isomeric MBA ligands is the difference in the repulsive Coulomb energy ${ }^{42}$ between the negative charges held by the carboxylic groups and the negative charge held by the gold core. $m$-MBA and, in particular, $o$-MBA ligands will lead to stronger repulsive Coulomb energy that might favor fragmentation. Importance of repulsive Coulomb energy is emphasized by the charge state distributions in Figure 1 and CCS values.
In this last section, we aim at evaluating the emissive properties of $\mathrm{Au}_{25}(\mathrm{MBA})_{18}$ isomers. For all $\mathrm{Au}_{25}(\mathrm{MBA})_{18}$ isomeric clusters, we found no measurable one-photon excited fluorescence [in the visible range] under UV-vis light (350$500 \mathrm{~nm}$ excitation) both in the solid state and in solution, meaning that the quantum yields (QYs) are much lower than $10^{-5}$ (limit of the sensitivity of our instrument). To our knowledge, no fluorescence spectra were reported for gold clusters capped with MBA as ligands, while, for instance, an NIR band centered at $\sim 700 \mathrm{~nm}$ is usually observed for $\mathrm{Au}_{25}(\mathrm{SG})_{18}$ in water with $\mathrm{QY}$ of $\sim 10^{-3}$. $^{43}$ This result is puzzling. Indeed, MBA ligands possess all the ingredients to enable fluorescence: (i) the benzene moiety allows for the ligand's capability of donating electron density to the metal core via the $\mathrm{S}-\mathrm{Au}$ bond (i.e., charge transfer capability of the ligand) and (ii) the carboxylic group is an electron-rich group that can possibly interact with the gold cluster surface (in particular with $o$-MBA isomer). However, the substituent in MBA ( $-\mathrm{SH},-$ phenyl, and $-\mathrm{COOH}$ groups) allows for a strong mesomeric effect, which tends to render in one hand more negative the carboxylic group and on the other hand more positive the $\mathrm{S}$ atom. It was suggested by $\mathrm{Wu}$ and $\mathrm{Jin}^{8}$ that the NIR fluorescence in $\mathrm{Au}_{25} \mathrm{SR}_{18}$ originated from charge transfer from the ligands to the metal nanoparticle core through the $\mathrm{Au}-\mathrm{S}$ bonds. This mesomeric effect (leading to more positive sulfur atom) might avoid the charge transfer from the sulfur atom of the thiolate ligand to the gold center, thus inhibiting the red fluorescence band. Of note, this mesomeric effect is not supposed to affect the metal-metal transition in the gold core (see below).

Interestingly, the $\mathrm{Au}_{25}(\mathrm{MBA})_{18} \mathrm{NCs}$ are nonfluorescent in the visible range with a one-photon excitation, whereas an intense two-photon excitation fluorescence (TPEF) spectrum was observed with an excitation at $800 \mathrm{~nm}$. TPEF spectra for $\mathrm{Au}_{25}(p-\mathrm{MBA})_{18}, \quad \mathrm{Au}_{25}(m-\mathrm{MBA})_{18}, \quad \mathrm{Au}_{25}(o-\mathrm{MBA})_{18}$, and $\mathrm{Au}_{25}(\mathrm{SG})_{18}$ are shown in Figure 4, and are compared to the TPEF spectrum of fluorescein dye used as a reference. A broad band in the visible range between 400 and $600 \mathrm{~nm}$ and centered at about $470 \mathrm{~nm}$ is observed, as already reported for other gold-thiolate systems. ${ }^{44,45}$ Two-photon excitation involved different electronic transitions than those involved

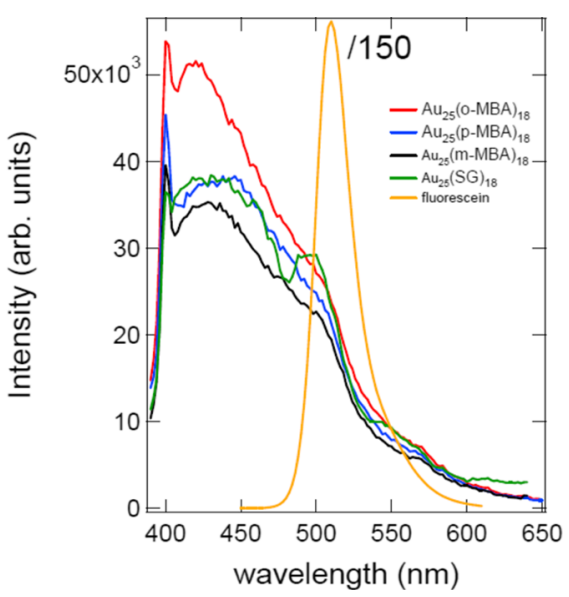

Figure 4. Two-photon excited fluorescence (TPEF) spectra for $\mathrm{Au}_{25}(\mathrm{MBA})_{18}$ isomer NCs $(25 \mu \mathrm{M})$ and $\mathrm{Au}_{25}(\mathrm{SG})_{18} \mathrm{NCs}(25 \mu \mathrm{M})$ as a function of wavelength for an excitation wavelength at $800 \mathrm{~nm}$. The TPEF spectrum of fluorescein $(10 \mu \mathrm{M})$ is given for comparison. 
in one-photon excitation. ${ }^{46}$ This two photon excited photoemission can be attributed to transitions within the metal core. $^{47}$ Interestingly, TPEF spectra for $\mathrm{Au}_{25}(p-\mathrm{MBA})_{18}$, $\mathrm{Au}_{25}(m-\mathrm{MBA})_{18}, \mathrm{Au}_{25}(o-\mathrm{MBA})_{18}$, and $\mathrm{Au}_{25}(\mathrm{SG})_{18}$ are very similar both in band-shape and band intensity. Because this band is thought to be due to transitions within the metal core, the nature of the ligand is supposed not to play a significant role, as experimentally observed. This is, as already outlined, totally different than what is observed for one photon excitation fluorescence which involves ligand-core excitation.

First, hyperpolarizability of the $\mathrm{Au}_{25}(\mathrm{MBA})_{18} \mathrm{NCs}$ was also obtained using the HRS technique. ${ }^{17}$ The HRS intensity was recorded for several concentrations of the NCs dispersed in aqueous solutions (see Figure S6 in the Supporting Information), and short-range spectra were recorded around the HRS wavelength. The hyperpolarizabilities in units of $10^{-30}$ esu for $\mathrm{Au}_{25}(p-\mathrm{MBA})_{18}, \mathrm{Au}_{25}(m-\mathrm{MBA})_{18}$, and $\mathrm{Au}_{25}(o-\mathrm{MBA})_{18}$ NCs were found to be $179 \pm 18,203 \pm 20$, and $214 \pm 21$, respectively. This slight relative increase in hyperpolarizabilities might be the signature of slightly more asymmetric structures induced by steric hindrance that increases between $p$-, $m$-, and $o$-MBA isomers. On the other hand, MBA has an aromatic cycle with nonnegligible hyperpolarizability. The latter will not be the same for the three isomers. The resulting hyperpolarizability is therefore difficult to predict simply. Of note, these values are only slightly higher than the one reported for $\mathrm{Au}_{25}(\mathrm{SG})_{18}(128(1))$ and $\mathrm{Au}_{25}(\mathrm{cys})_{18}(163(4)) .{ }^{17} \mathrm{SG}$ and cysteine (cys) are chiral ligands, while MBA is not. Thus, the main contribution to hyperpolarizabilities is not due to the chirality of the surface capping shell, but more probably to ligand-induced asymmetry in the gold core structure. These results contrast with the findings reported by Knoppe et al. ${ }^{18}$ where $\left[\mathrm{Au}_{25}\left(\mathrm{SCH}_{2} \mathrm{CH}_{2} \mathrm{Ph}\right)_{18}\right]^{0}$ presented no measurable hyperpolarizability values. This difference might be explained by the fact that in our clusters, the gold core holds a negative charge $(-1)$, while in $\left[\mathrm{Au}_{25}\left(\mathrm{SCH}_{2} \mathrm{CH}_{2} \mathrm{Ph}\right)_{18}\right]$, the gold core is not charged. This negative charge might induce some asymmetry in the gold core ${ }^{48}$ and might be the key ingredient for enhanced hyperpolarizability observed for $\left[\mathrm{Au}_{25}(\mathrm{SR})_{18}\right]^{-1}$ NCs.

\section{CONCLUSIONS}

In summary, $\mathrm{Au}_{25}(\mathrm{MBA})_{18} \mathrm{NCs}$ using the three isomers of mercaptobenzoic acids $(p / m / o-M B A)$ as capping ligands were synthesized using a simple "bottom-up" size focusing two-step protocol. An isomeric effect of mercaptobenzoic acids on the yield of synthesis of $A_{25}(\mathrm{MBA})_{18} \mathrm{NCs}$ is observed and may be explained qualitatively based on steric hindrance of the carboxylic group. The relative stability of the gas-phase multiply deprotonated $\mathrm{Au}_{25}(\mathrm{MBA})_{18}$ ions was investigated by CID. Again, an isomeric effect of mercaptobenzoic acids on the gas-phase stability of $\mathrm{Au}_{25}(\mathrm{MBA})_{18} \mathrm{NCs}$ is observed which was attributed to the $\mathrm{Au}-\mathrm{S}$ interfacial bond stress. We also investigated their optical properties. The absorption spectra of $\mathrm{Au}_{25}(\mathrm{MBA})_{18}$ isomers were very similar and showed multiple bands at 690,470 , and $430 \mathrm{~nm}$ and are very similar to reported $\left[\mathrm{Au}_{25}(\mathrm{SR})_{18}\right]^{-} \mathrm{NCs}$ with different ligands. For all $\mathrm{Au}_{25}(\mathrm{MBA})_{18}$ isomeric clusters, we found no measurable one-photon excited fluorescence under UV-vis light both in the solid state and in solution. We also investigated their NLO properties after two-photon absorption. Two-photon excited emission spectra and first hyperpolarizabilities, as obtained by the HRS technique, of these isomeric clusters are presented. It is found that the impact of the charge on the symmetry of the gold core may be a key parameter to the observed exaltation of the first hyperpolarizabilities of the investigated clusters. The results are discussed in terms of the possible isomeric effect on the metal-to-metal excitations and the ability upon excitation of charge transfer from the ligands to the metal NC.

\section{EXPERIMENTAL SECTION}

4.1. Materials. Tetrachloroauric(III) acid trihydrate$\left(\mathrm{HAuCl}_{4} \cdot 3 \mathrm{H}_{2} \mathrm{O}\right)$, 4-mercaptobenzoic $\operatorname{acid}(p-\mathrm{MBA})$, and 3mercaptobenzoic acid ( $m$-MBA) were obtained from Acros Organics; thiosalicylic acid (2-mercaptobenzoic acid, $o$-MBA), tributylamine, and ammonium acetate were obtained from Sigma-Aldrich; borane-trimethylamine complex was obtained from Alfa Aesar; and methanol and diethyl ether were obtained from VWR. Milli-Q water with a resistivity of $18.2 \mathrm{M} \Omega \mathrm{cm}$ was used for all experiments.

All glasswares were cleaned with aqua-regia, rinsed with Milli-Q water, and dried before use.

4.2. Synthesis of $\mathrm{Au}_{25} \mathrm{MBA}_{18}$ Clusters. A similar synthetic condition was used for three (para, meta, or ortho) mercaptobenzoic acid-gold clusters.

Mercaptobenzoic acid $(5.1 \mathrm{mmol}, 79 \mathrm{mg})$ is first dissolved in $40 \mathrm{~mL}$ of methanol and $4 \mathrm{~mL}$ of tributylamine. Then, tetrachloroauric acid trihydrate $(2.54 \mathrm{mmol}, 100 \mathrm{mg})$ is added at an ambient condition and stirred $30 \mathrm{mn}$ to form a gold thiolate/tributylamine complex.

Then, to induce a slow reduction of gold, $200 \mathrm{mg}$ of trimethylamine borane is added under stirring for $2 \mathrm{~h}$ before adding another $200 \mathrm{mg}$. The solution is left under stirring overnight for $24 \mathrm{~h}$ to achieve the formation of the clusters.

Of note, tributylamine first solubilizes clusters and precursors in methanol. Without tributylamine (or with ammoniac), precipitation occurs.

4.3. Purification. Precipitation of the clusters is induced by adding $1 \mathrm{~mL}$ of $10 \% \mathrm{NH}_{4} \mathrm{OH}$ solution and $30 \mathrm{~mL}$ of diethyl ether. After centrifugation, the supernatant which contains unwanted products is removed. Another cycle of dissolution/ precipitation $\left(1 \mathrm{~mL} \mathrm{H} \mathrm{H}_{2} \mathrm{O} ; 5 \mathrm{~mL}\right.$ of $\mathrm{MeOH}$ and $20 \mathrm{~mL}^{\text {of }} \mathrm{Et}_{2} \mathrm{O}$ ) is done.

Purification of the $\mathrm{Au}_{25}(\mathrm{MBA})_{18}$ cluster is done by selective precipitation. The precipitate is dissolved in $5 \mathrm{~mL}$ of water, and then $700 \mathrm{mg}$ of ammonium acetate is added, followed by 20 $\mathrm{mL}$ of $\mathrm{MeOH}$. Under these conditions, a precipitate appears which is separated by centrifugation. With $m$-MBA, very few precipitates can be extracted and are essentially a mixture of bigger clusters than $\mathrm{Au}_{25}$. With $p$-MBA, this precipitate is essentially composed of $\mathrm{Au}_{36}(p-\mathrm{MBA})_{24}$ with a good purity. For these two ligands, $\mathrm{Au}_{25}(\mathrm{MBA})_{18}$ is soluble in the supernatant and can be precipitated by adding $\mathrm{Et}_{2} \mathrm{O}$. With $o$ MBA, this precipitate is essentially $\mathrm{Au}_{25}(\mathrm{MBA})_{18}$. The supernatant contains a population of smaller clusters. In all cases, two cycles of dissolution/precipitation are done to improve purity of the cluster at the end, the last one using a minimum of water $/ \mathrm{MeOH}$ precipitate by $\mathrm{Et}_{2} \mathrm{O}$. At the end, the powder is dried overnight at air.

4.4. Polyacrylamide Gel Electrophoresis. PAGE separation was carried out using a vertical gel electrophoresis unit with a size of $0.2 \mathrm{~cm} \times 20 \mathrm{~cm} \times 20 \mathrm{~cm}$. The separating and stacking gels were prepared from acrylamide monomers with the total contents of 35 and 7 wt \%, respectively [acrylamidebis(acrylamide) 94:6]. The eluting buffer is a standard TBE buffer ( $89 \mathrm{mM}$ Tris, $89 \mathrm{mM}$ boric acid, $2 \mathrm{mM}$ ethyl- 
enediaminetetraacetic acid). The as-prepared $\mathrm{Au}(\mathrm{MBA})$ clusters were dissolved in a $15 \%(\mathrm{v} / \mathrm{v})$ glycerol/water solution (6 mg in $100 \mu \mathrm{L}$ ). The sample solutions were loaded onto the stacking gel $(10 \mu \mathrm{L}$ per well $)$ and eluted for $7 \mathrm{~h}$ at a constant voltage mode $(150 \mathrm{~V})$ to achieve sufficient separation.

4.5. Ion Mobility and Mass Spectrometry (IM-MS). IM-MS measurement was performed on a home-built setup described elsewhere ${ }^{49}$ and is based on a Maxis Impact Quadrupole-time-of-flight mass spectrometer (Bruker, Bremen, Germany). Solutions were prepared in water at a concentration of approximately $25 \mu \mathrm{M}$ and directly sprayed using the original electrospray source of the instrument. The source was operated at relatively low drying gas temperature $\left(80{ }^{\circ} \mathrm{C}\right)$, and all ion transfer optics were set to gentle conditions in order to minimize cluster fragmentation. Namely, the amplitude of the radiofrequency voltages and the dc gradients along the path were minimized.

MS and tandem-MS measurements were done by turning off the ion bunching in the IMS cell, and then allowing continuous injection of the ions in the Bruker instrument. CID experiments were done in the tandem-MS mode by selecting the ions using a quadrupole filter before injecting them in a collision cell filled with nitrogen as a collision gas. Fragment ions were finally detected after a time-of-flight measurement. The CE was varied by controlling the voltage drop between the exit lens of the quadrupole and the entrance lens of the collision cell. The CEs reported in the paper are given to allow comparison between the different species, taking into account both the voltage drop $V_{\text {coll }}$ and the charge $z$ of the ions: $\mathrm{CE}=$ $z V_{\text {coll }}$.

Ion mobility measurements were done using a $79 \mathrm{~cm}$-long drift tube filled with 4.0 Torr helium at room temperature. The arrival time of the ions was recorded as a function of the drift voltage across the tube (from 150 to $500 \mathrm{~V}$ ), thus allowing absolute cross section (CCS) measurements based on the Mason-Schamp equation. ${ }^{50}$ We estimated the overall error on the absolute value determined by this procedure to be $2 \%$.

4.6. Absorption and Emission Measurements. UV-vis spectra in solution were recorded using an AvaSpec-2048 fiber optic spectrometer and an AvaLight-DH-S deuterium halogen light source. Fluorescence spectra were measured using a Fluoromax-4 HORIBA fluorescence spectrophotometer.

4.7. HRS and TPEF Measurements. The light source for the present HRS and TPEF experiments was a mode-locked femtosecond Ti:sapphire laser delivering at the fundamental wavelength of $800 \mathrm{~nm}$ pulses with a duration of about $140 \mathrm{fs}$ at a repetition rate of $76 \mathrm{MHz}$. After passing through a low-pass filter to remove any unwanted harmonic light generated prior to the cell, the fundamental beam of about $300 \mathrm{~mW}$ was focused by a microscope objective into a $1 \mathrm{~cm}$ spectrophotometric cell containing the aqueous solution. The HRS (or TPEF) light was collected at an angle of $90^{\circ}$ from the incident direction by a $2.5 \mathrm{~cm}$ focal length lens. The second harmonic light was separated from its linear counterpart by a high-pass filter and a monochromator positioned at the second harmonic wavelength. The HRS light was then detected with a photomultiplier tube (model H11890-210, Hamamatsu) and the pulses produced were counted with a photon counter.

\section{ASSOCIATED CONTENT}

\section{(S) Supporting Information}

The Supporting Information is available free of charge on the ACS Publications website at DOI: 10.1021/acsomega. 8 b02615.

PAGE for Au:SG and Au:MBA clusters, isotopic distributions for the 3- charge state of $\mathrm{Au}_{25}(\mathrm{MBA})_{18}$, ATDs for the different charge states of $\mathrm{Au}_{25} \mathrm{MBA}_{18}$, collision cross section for $\mathrm{Au}_{25}(\mathrm{MBA})_{18}$, relative populations of the different ions observed after collisional activation of the 4- charge state of the different isomeric forms of $\mathrm{Au}_{25}(\mathrm{MBA})_{18}$, and HRS intensity for the three $\mathrm{Au}_{25}(\mathrm{MBA})_{18}$ isomers (PDF)

\section{AUTHOR INFORMATION}

\section{Corresponding Author}

*E-mail: rodolphe.antoine@univ-lyon1.fr (R.A.).

ORCID

Fabien Chirot: 0000-0001-9115-9233

Philippe Dugourd: 0000-0003-4395-1140

Pierre-François Brevet: 0000-0002-9097-0187

Rodolphe Antoine: 0000-0001-5682-8550

Notes

The authors declare no competing financial interest.

\section{REFERENCES}

(1) Jin, R.; Zeng, C.; Zhou, M.; Chen, Y. Atomically Precise Colloidal Metal Nanoclusters and Nanoparticles: Fundamentals and Opportunities. Chem. Rev. 2016, 116, 10346-10413.

(2) Chakraborty, I.; Pradeep, T. Atomically Precise Clusters of Noble Metals: Emerging Link between Atoms and Nanoparticles. Chem. Rev. 2017, 117, 8208-8271.

(3) Parker, J. F.; Fields-Zinna, C. A.; Murray, R. W. The Story of a Monodisperse Gold Nanoparticle: Au25L18. Acc. Chem. Res. 2010, 43, 1289-1296.

(4) Zhu, M.; Aikens, C. M.; Hollander, F. J.; Schatz, G. C.; Jin, R. Correlating the Crystal Structure of A Thiol-Protected Au25Cluster and Optical Properties. J. Am. Chem. Soc. 2008, 130, 5883-5885.

(5) Heaven, M. W.; Dass, A.; White, P. S.; Holt, K. M.; Murray, R. W. Crystal Structure of the Gold Nanoparticle [N(C8H17)4][Au25(SCH2CH2Ph)18]. J. Am. Chem. Soc. 2008, 130, 3754-3755.

(6) Aikens, C. M. Origin of Discrete Optical Absorption Spectra of M25(SH)18- Nanoparticles ( $\mathrm{M}=\mathrm{Au}, \mathrm{Ag})$. J. Phys. Chem. C 2008, 112, 19797-19800.

(7) Akola, J.; Walter, M.; Whetten, R. L.; Häkkinen, H.; Grönbeck, H. On the Structure of Thiolate-Protected Au25. J. Am. Chem. Soc. 2008, 130, 3756-3757.

(8) Wu, Z.; Jin, R. On the Ligand's Role in the Fluorescence of Gold Nanoclusters. Nano Lett. 2010, 10, 2568-2573.

(9) Knoppe, S.; Bürgi, T. Chirality in Thiolate-Protected Gold Clusters. Acc. Chem. Res. 2014, 47, 1318-1326.

(10) Yao, H. Chiral ligand-protected gold nanoclusters: Considering the optical activity from a viewpoint of ligand dissymmetric field. Prog. Nat. Sci.: Mater. Int. 2016, 26, 428-439.

(11) Tofanelli, M. A.; Salorinne, K.; Ni, T. W.; Malola, S.; Newell, B.; Phillips, B.; Häkkinen, H.; Ackerson, C. J. Jahn-Teller effects in Au25(SR)18. Chem. Sci. 2016, 7, 1882-1890.

(12) Kwak, K.; Lee, D. Electrochemical Characterization of WaterSoluble Au25 Nanoclusters Enabled by Phase-Transfer Reaction. J. Phys. Chem. Lett. 2012, 3, 2476-2481.

(13) García-Raya, D.; Madueño, R.; Blázquez, M.; Pineda, T. Electrochemistry of Molecule-like Au25 Nanoclusters Protected by Hexanethiolate. J. Phys. Chem. C 2009, 113, 8756-8761.

(14) Kang, X.; Chong, H.; Zhu, M. Au25(SR)18: the captain of the great nanocluster ship. Nanoscale 2018, 10, 10758-10834. 
(15) Antoine, R.; Bonacic-Koutecky, V. Liganded Silver and Gold Quantum Clusters. Towards a New Class of Nonlinear Optical Nanomaterials; Springer: Cham, 2018.

(16) Antoine, R. Atomically precise clusters of gold and silver: Towards a new class of nonlinear optical nanomaterials. Frontier Res.Today 2018, 1, 01001.

(17) Russier-Antoine, I.; Bertorelle, F.; Vojkovic, M.; Rayane, D.; Salmon, E.; Jonin, C.; Dugourd, P.; Antoine, R.; Brevet, P.-F. Nonlinear optical properties of gold quantum clusters. The smaller the better. Nanoscale 2014, 6, 13572-13578.

(18) Van Steerteghem, N.; Van Cleuvenbergen, S.; Deckers, S.; Kumara, C.; Dass, A.; Häkkinen, H.; Clays, K.; Verbiest, T.; Knoppe, S. Symmetry breaking in ligand-protected gold clusters probed by nonlinear optics. Nanoscale 2016, 8, 12123-12127.

(19) Parrish, K. A.; King, M.; Ligare, M. R.; Johnson, G. E.; Hernández, H. Role of sterics in phosphine-ligated gold clusters. Phys. Chem. Chem. Phys. 2018, DOI: 10.1039/c8cp04961k.

(20) Chen, Y.; Zeng, C.; Kauffman, D. R.; Jin, R. Tuning the Magic Size of Atomically Precise Gold Nanoclusters via Isomeric Methylbenzenethiols. Nano Lett. 2015, 15, 3603-3609.

(21) Azubel, M.; Koh, A. L.; Koyasu, K.; Tsukuda, T.; Kornberg, R. D. Structure Determination of a Water-Soluble 144-Gold Atom Particle at Atomic Resolution by Aberration-Corrected Electron Microscopy. ACS Nano 2017, 11, 11866-11871.

(22) Tero, T.-R.; Malola, S.; Koncz, B.; Pohjolainen, E.; Lautala, S.; Mustalahti, S.; Permi, P.; Groenhof, G.; Pettersson, M.; Häkkinen, H. Dynamic Stabilization of the Ligand-Metal Interface in Atomically Precise Gold Nanoclusters Au68 and Au144 Protected by metaMercaptobenzoic Acid. ACS Nano 2017, 11, 11872-11879.

(23) Lin, Y.-J.; Chen, P.-C.; Yuan, Z.; Ma, J.-Y.; Chang, H.-T. The isomeric effect of mercaptobenzoic acids on the preparation and fluorescence properties of copper nanoclusters. Chem. Commun. 2015, 51, 11983-11986.

(24) Wu, Z.; MacDonald, M. A.; Chen, J.; Zhang, P.; Jin, R. Kinetic Control and Thermodynamic Selection in the Synthesis of Atomically Precise Gold Nanoclusters. J. Am. Chem. Soc. 2011, 133, 9670-9673.

(25) Black, D. M.; Crittenden, C. M.; Brodbelt, J. S.; Whetten, R. L. Ultraviolet Photodissociation of Selected Gold Clusters: Ultraefficient Unstapling and Ligand Stripping of Au25(pMBA)18 and Au36(pMBA)24. J. Phys. Chem. Lett. 2017, 8, 1283-1289.

(26) Lu, Y.; Chen, W. Application of Mass Spectrometry in the Synthesis and Characterization of Metal Nanoclusters. Anal. Chem. 2015, 87, 10659-10667.

(27) Truillet, C.; Lux, F.; Tillement, O.; Dugourd, P.; Antoine, R. Coupling of HPLC with Electrospray Ionization Mass Spectrometry for Studying the Aging of Ultrasmall Multifunctional GadoliniumBased Silica Nanoparticles. Anal. Chem. 2013, 85, 10440-10447.

(28) Jin, R. Atomically precise metal nanoclusters: stable sizes and optical properties. Nanoscale 2015, 7, 1549-1565.

(29) Qian, H.; Zhu, M.; Wu, Z.; Jin, R. Quantum Sized Gold Nanoclusters with Atomic Precision. Acc. Chem. Res. 2012, 45, 14701479.

(30) Baksi, A.; Ghosh, A.; Mudedla, S. K.; Chakraborty, P.; Bhat, S.; Mondal, B.; Krishnadas, K. R.; Subramanian, V.; Pradeep, T. Isomerism in Monolayer Protected Silver Cluster Ions: An Ion Mobility-Mass Spectrometry Approach. J. Phys. Chem. C 2017, 121, 13421-13427.

(31) Baksi, A.; Harvey, S. R.; Natarajan, G.; Wysocki, V. H.; Pradeep, T. Possible isomers in ligand protected Ag11 cluster ions identified by ion mobility mass spectrometry and fragmented by surface induced dissociation. Chem. Commun. 2016, 52, 3805-3808.

(32) Ligare, M. R.; Baker, E. S.; Laskin, J.; Johnson, G. E. Ligand induced structural isomerism in phosphine coordinated gold clusters revealed by ion mobility mass spectrometry. Chem. Commun. 2017, 53, 7389-7392.

(33) Soleilhac, A.; Bertorelle, F.; Comby-Zerbino, C.; Chirot, F.; Calin, N.; Dugourd, P.; Antoine, R. Size Characterization of Glutathione-Protected Gold Nanoclusters in the Solid, Liquid and Gas Phases. J. Phys. Chem. C 2017, 121, 27733-27740.
(34) Comby-Zerbino, C.; Bertorelle, F.; Chirot, F.; Dugourd, P.; Antoine, R. Structural insights into glutathione-protected gold Au1012(SG)10-12 nanoclusters revealed by ion mobility mass spectrometry. Eur. Phys. J. D 2018, 72, 144.

(35) Poyer, S.; Comby-Zerbino, C.; Choi, C. M.; MacAleese, L.; Deo, C.; Bogliotti, N.; Xie, J.; Salpin, J.-Y.; Dugourd, P.; Chirot, F. Conformational Dynamics in Ion Mobility Data. Anal. Chem. 2017, $89,4230-4237$.

(36) Lermé, J.; Dugourd, P.; Hudgins, R. R.; Jarrold, M. F. Highresolution ion mobility measurements of indium clusters: electron spill-out in metal cluster anions and cations. Chem. Phys. Lett. 1999, 304, 19-22.

(37) Tomihara, R.; Hirata, K.; Yamamoto, H.; Takano, S.; Koyasu, K.; Tsukuda, T. Collision-Induced Dissociation of Undecagold Clusters Protected by Mixed Ligands [Au11(PPh3)8X2]+ $(\mathrm{X}=\mathrm{Cl}$, $\mathrm{C} \equiv \mathrm{CPh}$ ). ACS Omega 2018, 3, 6237-6242.

(38) Johnson, G. E.; Laskin, J. Understanding ligand effects in gold clusters using mass spectrometry. Analyst 2016, 141, 3573-3589.

(39) Black, D. M.; Bhattarai, N.; Whetten, R. L.; Bach, S. B. H. Collision-Induced Dissociation of Monolayer Protected Clusters Au144 and Au130 in an Electrospray Time-of-Flight Mass Spectrometer. J. Phys. Chem. A 2014, 118, 10679-10687.

(40) Hamouda, R.; Bertorelle, F.; Rayane, D.; Antoine, R.; Broyer, M.; Dugourd, P. Glutathione capped gold $\mathrm{AuN}(\mathrm{SG}) \mathrm{M}$ clusters studied by isotope-resolved mass spectrometry. Int. J. Mass Spectrom. 2013, 335, 1-6.

(41) Hirata, K.; Yamashita, K.; Muramatsu, S.; Takano, S.; Ohshimo, K.; Azuma, T.; Nakanishi, R.; Nagata, T.; Yamazoe, S.; Koyasu, K.; Tsukuda, T. Anion photoelectron spectroscopy of free [Au25(SC12H25)18]-. Nanoscale 2017, 9, 13409-13412.

(42) Vonderach, M.; Ehrler, O. T.; Matheis, K.; Karpuschkin, T.; Papalazarou, E.; Brunet, C.; Antoine, R.; Weis, P.; Hampe, O.; Kappes, M. M.; Dugourd, P. Probing electrostatic interactions and structural changes in highly charged protein polyanions by conformerselective photoelectron spectroscopy. Phys. Chem. Chem. Phys. 2011, 13, 15554-15558.

(43) Negishi, Y.; Nobusada, K.; Tsukuda, T. Glutathione-Protected Gold Clusters Revisited: Bridging the Gap between Gold(I)-Thiolate Complexes and Thiolate-Protected Gold Nanocrystals. J. Am. Chem. Soc. 2005, 127, 5261-5270.

(44) Bertorelle, F.; Russier-Antoine, I.; Calin, N.; Comby-Zerbino, C.; Bensalah-Ledoux, A.; Guy, S.; Dugourd, P.; Brevet, P.-F.; Sanader, Ž.; Krstić, M.; Bonačić-Koutecký, V.; Antoine, R. Au10(SG)10: A Chiral Gold Catenane Nanocluster with Zero Confined Electrons. Optical Properties and First-Principles Theoretical Analysis. J. Phys. Chem. Lett. 2017, 8, 1979-1985.

(45) Russier-Antoine, I.; Bertorelle, F.; Kulesza, A.; Soleilhac, A.; Bensalah-Ledoux, A.; Guy, S.; Dugourd, P.; Brevet, P.-F.; Antoine, R. Chiral supramolecular gold-cysteine nanoparticles: Chiroptical and nonlinear optical properties. Prog. Nat. Sci.: Mater. Int. 2016, 26, 455460.

(46) Russier-Antoine, I.; Bertorelle, F.; Hamouda, R.; Rayane, D.; Dugourd, P.; Sanader, Z.; Bonačić-Koutecký, V.; Brevet, P.-F.; Antoine, R. Tuning Ag29 nanocluster light emission from red to blue with one and two-photon excitation. Nanoscale 2016, 8, 28922898.

(47) Bonačić-Koutecký, V. Theoretical design of new class of optical materials based on small noble metal nanocluster-biomolecule hybrids and its potential for medical applications. Adv. Phys.: X 2017, 2, 695716.

(48) Russier-Antoine, I.; Bertorelle, F.; Calin, N.; Sanader, Z.; Krstić, M.; Comby-Zerbino, C.; Dugourd, P.; Brevet, P.-F.; BonačićKoutecký, V.; Antoine, R. Ligand-core NLO-phores: a combined experimental and theoretical approach to the two-photon absorption and two-photon excited emission properties of small-ligated silver nanoclusters. Nanoscale 2017, 9, 1221-1228.

(49) Simon, A.-L.; Chirot, F.; Choi, C. M.; Clavier, C.; Barbaire, M.; Maurelli, J.; Dagany, X.; MacAleese, L.; Dugourd, P. Tandem ion 
mobility spectrometry coupled to laser excitation. Rev. Sci. Instrum.

2015, 86, 094101.

(50) Revercomb, H. E.; Mason, E. A. Theory of plasma chromatography/gaseous electrophoresis. Review. Anal. Chem. 1975, 47, 970-983. 